\title{
放电态 $\mathrm{Li}-\mathrm{AgVO}_{3}$ 一次电池作为可充 $\mathrm{Li}-\mathrm{O}_{2}$ 电池再利用研究
}

\author{
李手卢艳莹雷凯翔李福军程方益* 陈军 \\ (南开大学 化学学院 先进能源材料化学教育部重点实验室 化学化工协同创新中心 天津 300071)
}

\begin{abstract}
摘要 废弃电池中活性材料再利用是目前处理废弃的一次电池既节约又节能的方法. 基于此, 本工作详细地研究了废 弃的 $\mathrm{Li}-\mathrm{AgVO}_{3}$ 一次电池作为可充 $\mathrm{Li}-\mathrm{O}_{2}$ 电池的再利用. 结果显示放电后的 $\mathrm{Li}-\mathrm{AgVO}_{3}$ 电池可以作为 $\mathrm{Li}^{-} \mathrm{O}_{2}$ 电池被再次激 活. 在 $\mathrm{Li}^{-} \mathrm{AgVO}_{3}$ 电池放电过程中, 原位生长在钒氧化物电极上的银纳米颗粒可以进一步有效地催化 $\mathrm{Li}^{-} \mathrm{O}_{2}$ 电池中氧还 原和氧析出反应(ORR/OER). 通过控制 $\mathrm{Li}^{-} \mathrm{AgVO}_{3}$ 一次电池的放电深度, 可以得到具有不同尺寸和分布状态的 $\mathrm{Ag}$ 纳米 颗粒的银/钒氧化物复合电极. 将这些不同放电状态的复合电极作为 $\mathrm{Li}^{-} \mathrm{O}_{2}$ 电池的空气正极并测试了它们的电化学性能. 电化学测试结果表明, 放电到 $2.3 \mathrm{~V}$ 的复合电极电化学性能最优, 比容量高达 $9000 \mathrm{mAh} \cdot \mathrm{g}_{\text {carbon }}{ }^{-1}$, 充放电过电位最低, 可稳定循环 95 周. 其优异电化学性能归因于银纳米颗粒合适的尺寸和均匀的分布, 明显提高了电极导电能力并为 ORR/OER 电催化反应提供了丰富的活性位点.
\end{abstract}

关键词 钛酸银; 银纳米颗粒; 锂一次电池; 锂氧电池; 循环利用; 氧还原/氧析出

\section{Resumption of the Discharged $\mathrm{Li}-\mathrm{AgVO}_{3}$ Primary Batteries for Rechargeable $\mathrm{Li}-\mathrm{O}_{2}$ Batteries}
Li, Ran
Lu, Yanying
Lei, Kaixiang
Li, Fujun
Cheng, Fangyi*
Chen, Jun

(Key Laboratory of Advanced Energy Materials Chemistry (Ministry of Education), College of Chemistry, Nankai University; Collaborative Innovation Center of Chemical Science and Engineering, Tianjin 300071, China)

\begin{abstract}
Recycling use is one of the energy and resource saving strategies to dispose depleted batteries, especially primary lithium batteries that employ electrode materials based on expensive and low-abundance elements. In this study, we report in detail the recycling use of discharged $\mathrm{Li}-\mathrm{AgVO}_{3}$ primary battery for rechargeable $\mathrm{Li}-\mathrm{O}_{2}$ battery. We demonstrate that the discharged $\mathrm{Li}-\mathrm{AgVO}_{3}$ cell, in which metallic silver nanoparticles $i n$-situ generated in the vanadium oxide nanowires cathode efficiently catalyze the oxygen reduction/evolution reactions (ORR/OER), can be resumed as rechargeable $\mathrm{Li}_{2} \mathrm{O}_{2}$ cells when they are exposed at $\mathrm{O}_{2}$ atmosphere. By controlling the discharge depths, we obtained different cathodes that were composed of vanadium oxide nanowires and silver nanoparticles. As the electrode was discharged to a lower voltage, more silver nanoparticles with larger particle size were distributed on the surface of vanadium oxides, as a result of the sequential reduction of $\mathrm{Ag}^{+}$to $\mathrm{Ag}^{0}$ and $\mathrm{V}^{5+}$ to $\mathrm{V}^{4+}$. Specifically, the average size of formed $\mathrm{Ag}$ nanoparticles was $15 \mathrm{~nm}$ and $70 \mathrm{~nm}$ at ceased discharge voltage of $2.9 \mathrm{~V}$ and $2.0 \mathrm{~V}$, respectively, while the formation of $\mathrm{V}^{4+}$ was observed at discharge voltage lower than 2.3 $\mathrm{V}$. Electrochemical tests indicated that the $\mathrm{Li}-\mathrm{O}_{2}$ cells assembled with the $\mathrm{AgVO}_{3}$ cathode discharged to $2.3 \mathrm{~V}\left(\mathrm{AgVO}_{3}-2.3\right)$ exhibited the highest specific capacity $\left(9000 \mathrm{mAh} \cdot \mathrm{g}_{\text {carbon }}{ }^{-1}\right)$, the lowest overpotential and robust cycling performance (up to 95 cycles at the current density of $\left.300 \mathrm{~mA} \cdot \mathrm{g}_{\text {carbon }}{ }^{-1}\right)$. The remarkable electrochemical performance of the Li- $\mathrm{O}_{2}$ battery with the $\mathrm{AgVO}_{3}-2.3$ cathode is attributed to the optimization of amount, size and distribution of generated silver nanoparticles that contribute to high electronic conductivity and abundant active sites for the ORR/OER. A combined analysis of electrochemical impedance spectroscopy, X-ray diffraction, and X-ray photoelectron spectroscopy confirmed that the $\mathrm{AgVO}_{3}-2.3$ cathode enables the reversible formation and decomposition of $\mathrm{Li}_{2} \mathrm{O}_{2}$ with lower charge transfer resistance on discharge and charge. The results presented here would provide new insight into the promising recycling application of depleted primary $\mathrm{Li}-\mathrm{AgVO}_{3}$ batteries in rechargeable high-capacity $\mathrm{Li}-\mathrm{O}_{2}$ batteries.
\end{abstract}

Keywords silver vanadium oxide; silver nanoparticles; lithium primary battery; Li-oxygen battery; recycling use; oxygen reduction/evolution

*E-mail: fycheng@nankai.edu.cn. Tel.: 022-23497717; Fax: 022-23509571

Received July 7, 2016; published September 30, 2016.

Supporting information for this article is available free of charge via the Internet at http://sioc-journal.cn.

Project supported by the National Natural Science Foundation of China (Nos. 21322101, 21231005), Ministry of Education (No. 113016A) and 111 Project (No. B12015).

项目受国家自然科学基金优秀青年基金(No. 21322101)和重点项目(No. 21231005)、教育部重点科技项目(No. 113016A)及 111 计划项目(No. B12015) 资助. 


\section{1 引言}

作为锂一次电池正极材料, 银钒氧化物(SVOs)因具 有较高的能量密度和良好的稳定性而备受青睐 ${ }^{[1 \sim 5]}$. 然 而, 由于 $A g 、 V$ 元素的价格昂贵、毒性高等缺点, 逐渐 引起人们对大量废弃 SVOs 材料所造成的资源浪费和环 境污染等影响的关注 ${ }^{[6]}$. 提高电极材料利用率是解决上 述问题一种行之有效的方法, 值得我们更多的研究 ${ }^{[7]}$. 将使用过的锂一次电池 SVOs 正极材料再次利用对于节 约能源和资源、降低环境污染、提高材料利用率具有重 要的意义. 此外, 锂离子电池的理论能量密度受限于自 身的化学特性, 因此开发新的高能量密度储能体系迫在 眉睫 ${ }^{[8 \sim 13]}$. $\mathrm{Li}-\mathrm{O}_{2}$ 电池作为锂离子电池最有潜力的替代者 之一, 能量密度高达 $3600 \mathrm{Wh} \cdot \mathrm{kg}^{-1}$, 近年来吸引了广泛 的研究兴趣 ${ }^{[14 ~ 19] . ~}{ }^{2}$ i- $\mathrm{O}_{2}$ 电池与锂离子电池在电池结构 和组成上具有相似性(如: 金属锂负极、有机电解液、隔 膜). 金属氧化物不仅是锂离子电池正极活性物质, 也 是理想的氧还原氧析出电催化材料, 可应用于 $\mathrm{Li}-\mathrm{O}_{2}$ 电 池空气正极 ${ }^{[20]}$. 因此, 将废旧的锂离子电池作为 $\mathrm{Li}^{-\mathrm{O}_{2}}$ 电池重新激活使用能够有效地提高电极材料的利用率. 这种新概念的可行性已经被本课题组最近在可充 $\mathrm{Li}-\mathrm{MnO}_{2}$ 电池再利用体系中所证实 ${ }^{[21]}$. $\mathrm{Li}-\mathrm{AgVO}_{3}$ 电池只 能放电一次, 电极材料利用率低, 因此实现对它的再次 利用具有重要研究价值.

作为锂一次电池正极材料, $\beta-\mathrm{AgVO}_{3}$ 放电时会原位

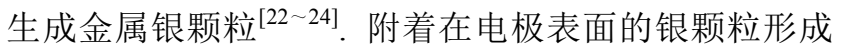
的导电网络为电子提供了有效的传输路径从而提高了 电极的电导率. Takeuchi 课题组 ${ }^{[25]}$ 报道了银导电网络的 原位生成对于 $\mathrm{Li}-\mathrm{Ag}_{2} \mathrm{VP}_{2} \mathrm{O}_{8}$ 电池性能的影响. 在 $\mathrm{Li}-\mathrm{Ag}_{2} \mathrm{VP}_{2} \mathrm{O}_{8}$ 电池体系中, 双金属正极材料 $\mathrm{Ag}_{2} \mathrm{VP}_{2} \mathrm{O}_{8}$ 放 电时 $\mathrm{Ag}^{+}$被还原为 $\mathrm{Ag}^{0}$, 在电极表面形成导电网络, 电 极导电性显著提高, 从而抑制了电池容量随放电倍率的 提高而衰减. 此外, 在水系及非水系 $\mathrm{Li}^{-} \mathrm{O}_{2}$ 电池中, 银纳 米颗粒作为良好的 ORR/OER 催化剂已经被广泛研 究 ${ }^{[26-29]}$. 研究表明, 以银纳米颗粒为正极催化剂, $\mathrm{Li}-\mathrm{O}_{2}$ 电池的电化学性能得到显著提升, 并且银纳米颗粒的尺 寸对 $\mathrm{Li}^{-} \mathrm{O}_{2}$ 电池性能具有重要的影响 ${ }^{[30 \sim 31]}$. 在一次电池 放电过程中原位生成的银纳米颗粒使放电后的 $\mathrm{Li}-\mathrm{AgVO}_{3}$ 一次电池被活化而作为 $\mathrm{Li}-\mathrm{O}_{2}$ 电池再次利用, 这种提高电极材料利用率的新方法目前还未见相关报 道. 深入认识 $\mathrm{Li}-\mathrm{AgVO}_{3}$ 电池放电过程中生成的银纳米 颗粒的特性对 $\mathrm{Li}-\mathrm{O}_{2}$ 电池性能的影响有助于我们实现对 于 $\mathrm{Li}-\mathrm{AgVO}_{3}$ 电池的高效重复利用.

本工作报道了放电后的 $\mathrm{Li}-\mathrm{AgVO}_{3}$ 一次电池在氧气 参与下作为 $\mathrm{Li}-\mathrm{O}_{2}$ 电池的再利用性能. 研究结果显示, 在 $\mathrm{Li}-\mathrm{AgVO}_{3}$ 电池放电过程中, 原位生成的银纳米颗粒 的尺寸和分布取决于电池的放电深度, 并对 $\mathrm{Li}-\mathrm{O}_{2}$ 电池 的电化学性能具有重要影响. 与纯碳电极相比, 以放电 态的 $\mathrm{AgVO}_{3}$ 电极为空气正极的 $\mathrm{Li}^{-} \mathrm{O}_{2}$ 电池表现出了较低
的充放电过电位, 较高的比容量和持久的循环性能. 尤 其是以放电到 $2.3 \mathrm{~V}$ 的 $\mathrm{AgVO}_{3}$ 电极为正极的 $\mathrm{Li}-\mathrm{O}_{2}$ 电池 表现出了最优异的电化学性能. 将放电后的一次电池再 次激活，这种新方法对于提高电极材料利用率和节约资 源等方面具有重要意义并为电极材料的回收利用提供 了新思路.

\section{2 结果与讨论}

\section{1 材料表征}

本工作以 $\mathrm{NH}_{4} \mathrm{VO}_{3}$ 和 $\mathrm{AgNO}_{3}$ 为原料通过水热法制 备了 $\beta-\mathrm{AgVO}_{3}$. 图 1(a)是所制备 $\beta-\mathrm{AgVO}_{3}$ 的 XRD 谱图, 样品的所有衍射峰均能与单斜相 $\beta-\mathrm{AgVO}_{3}$ (JCPDS No. 86-1154)标准卡片很好地对应并且没有检测到其它相的 生成，这表明了所制备样品具有较好结晶度和较高纯 度. 如图 1(b)所示, 单斜 $\beta-\mathrm{AgVO}_{3}$ 具有网状结构, 其网 状结构由无数个 $\mathrm{Z}$ 形的 $\left[\mathrm{V}_{4} \mathrm{O}_{12}\right]_{n}$ 链构成, 双链之间由银 原子相连接, 每个单链由共边 $\mathrm{VO}_{6}$ 八面体组成. 每个
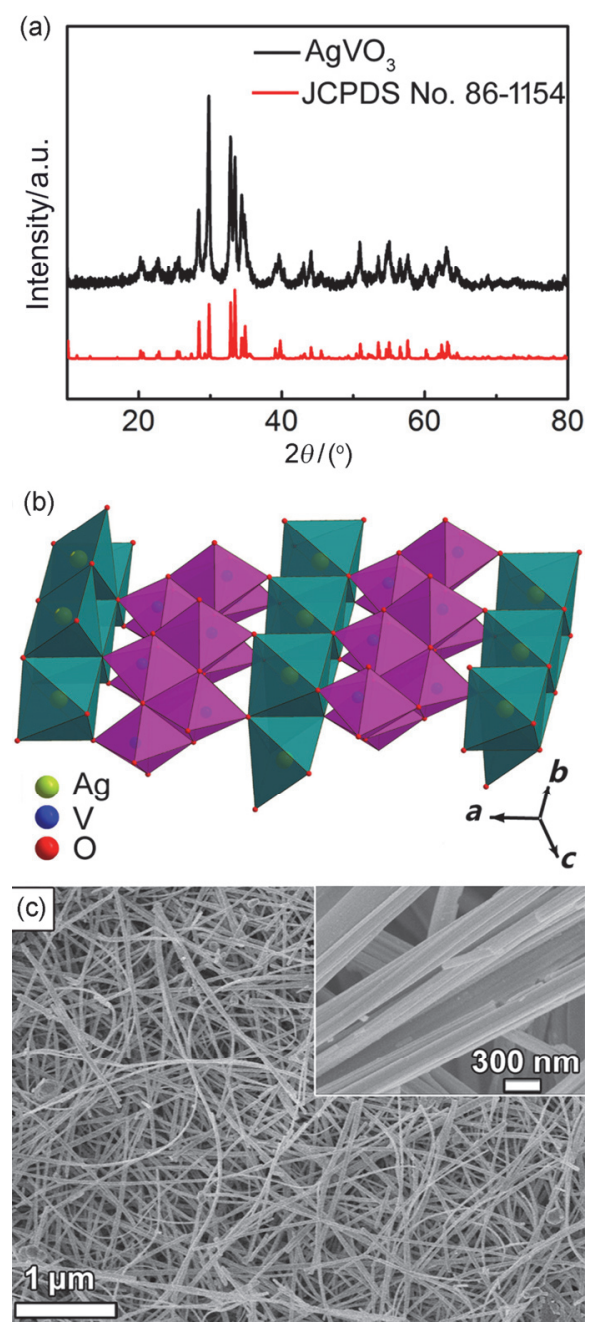

图 $1 \beta-\mathrm{AgVO}_{3}$ 纳米线的(a)XRD 谱图、(b)晶格结构和(c)SEM 图像 Figure 1 (a) XRD patterns, (b) crystal structure and (c) SEM images of the as synthesized $\beta-\mathrm{AgVO}_{3}$ nanowires 
$\mathrm{AgVO}_{3}$ 晶胞中存在三种银原子的配位环境: (i) 6 个氧原 子在顶点配位的规则八面体; (ii)周围氧原子 5 配位形成 的四方锥; (iii)由键连氧原子 7 配位构成的单帽三棱柱. 具有三维结构的 $\beta-\mathrm{AgVO}_{3}$ 通式为 $\mathrm{Ag}\left[\mathrm{Ag}_{3} \mathrm{~V}_{4} \mathrm{O}_{12}\right]$, 银原子 位于棱柱的孔道内, 使其在放电过程中具有更高的活 性 ${ }^{[32]}$. 图 1(c) 是 $\beta-\mathrm{AgVO}_{3}$ 在不同放大倍数下的扫描图 像, 可看出 $\beta-\mathrm{AgVO}_{3}$ 呈现尺寸较均匀的纳米线形貌, 纳 米线长度约为 $5 \mu \mathrm{m}$, 平均直径为 $200 \mathrm{~nm}$. 以上结果表 明通过水热法制备了具有高纯度和高结晶度的 $\beta-\mathrm{AgVO}_{3}$ 纳米线.

\section{2 电化学性能}

将以 $\beta-\mathrm{AgVO}_{3}$ 纳米线为正极所组装的 $\mathrm{Li}-\mathrm{AgVO}_{3}$ 一 次电池在 $100 \mathrm{~mA} \cdot \mathrm{g}^{-1}$ 电流密度下放电, 所得放电曲线 如图 2(a)所示, 在 $2.9 \mathrm{~V}$ 和 $2.3 \mathrm{~V}$ 左右观察到两个放电平 台, 分别对应于银和钒两个不同的氧化还原反应中心. 如图 2(b)所示, 采用 XRD 分析了处于 5 个不同放电状态 的 $\mathrm{AgVO}_{3}$ 电极(pristine, 2.9, 2.6, 2.3 and $2.0 \mathrm{~V}$ )的组成, 原始电极的 XRD 主要特征峰与所制备的 $\beta-\mathrm{AgVO}_{3}$ 的特 征峰一致. 当 $\mathrm{AgVO}_{3}$ 电池被放电到 $2.9 \mathrm{~V}$ 时, $\mathrm{AgVO}_{3}$ 的 衍射峰消失, 只有单质 $\mathrm{Ag}^{0}$ (JCPDS No. 65-2781)的衍射 峰被检测到. 这是由于 $\mathrm{AgVO}_{3}$ 结构的坍塌同时 $\mathrm{Ag}^{+}$被还 原为 $\mathrm{Ag}^{0}$ 引起的. 随着放电程度的加深, $\mathrm{Ag}^{+}$持续被还

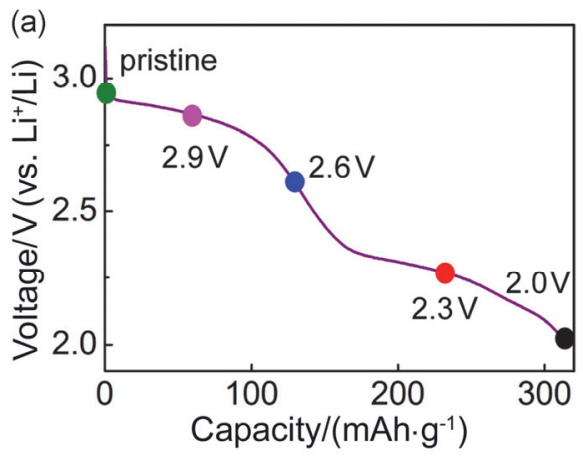

原, 所以 $\mathrm{Ag}^{0}$ 的峰强度逐渐增强. 当 $\mathrm{AgVO}_{3}$ 电池最终被 放电到 $2.0 \mathrm{~V}, \mathrm{Ag}^{0}$ 表现出了最强的 XRD 衍射峰. 由此可 知, $\mathrm{Ag}^{0}$ 的生成量与 $\mathrm{Li}-\mathrm{AgVO}_{3}$ 一次电池的放电深度密切 相关.

我们采用 XPS (X 射线光电子能谱)进一步检测了不 同放电状态的 $\mathrm{AgVO}_{3}$ 电极的化学组成变化. 图 3(a)是 $\operatorname{Ag} 3 \mathrm{~d}$ 的 XPS 信号峰, 在 368.5 和 $374.4 \mathrm{eV}$ 处有一对分 别对应于 $\mathrm{Ag}^{0} 3 \mathrm{~d}_{5 / 2}$ 和 $3 \mathrm{~d}_{3 / 2}$ 的信号峰. $\mathrm{Ag}^{+}$的 $3 d_{5 / 2}$ 和 $3 d_{3 / 2}$ 信号峰分别位于 367.5 和 $373.5 \mathrm{eV}$ 处. 从图中可以明显 地看出, 随着放电过程的进行, $\mathrm{Ag}^{+}$的峰强度逐渐降低. 相反, $\mathrm{Ag}^{0}$ 的峰强度逐渐增强. 这表明在 $\mathrm{Li}-\mathrm{AgVO}_{3}$ 一次 电池的放电过程中, $\mathrm{Ag}^{+}$逐渐被还原为 $\mathrm{Ag}^{0}$. 图 3(b) 显示 了不同放电状态下 $\mathrm{V} 2 \mathrm{p}$ 的 XPS 信号峰, 在初始状态与放 电至 $2.9 \mathrm{~V}$ 和 $2.6 \mathrm{~V}$ 的 $\mathrm{AgVO}_{3}$ 电极中只观察到一对位于 517.0 和 $524.3 \mathrm{eV}$ 处的信号峰, 分别对应于 $\mathrm{V}^{5+} 2 \mathrm{p}_{3 / 2}$ 和 $2 \mathrm{p}_{1 / 2}$. 这表明在此放电阶段放电容量仅来源于 $\mathrm{Ag}^{+}$的还 原. 当放电到 $2.3 \mathrm{~V}$ 和 $2.0 \mathrm{~V}, \mathrm{~V}^{4+}$ 的信号峰出现在 515.8 和 $522.5 \mathrm{eV}$ 处，分别对应于 $\mathrm{V}^{4+} 2 \mathrm{p}_{3 / 2}$ 和 $2 \mathrm{p}_{1 / 2}$. 这表明当 $\mathrm{AgVO}_{3}$ 电极的放电程度加深引发了 $\mathrm{V}^{5+}$ 还原为 $\mathrm{V}^{4+}$ 的电 化学反应. $\mathrm{Ag}^{+} / \mathrm{Ag}$ 和 $\mathrm{V}^{5+} / \mathrm{V}^{4+}$ 这两个氧化还原中心对应 于 $\mathrm{AgVO}_{3}$ 电极的放电过程中的两个放电平台, 与图 2(a) 相对应.

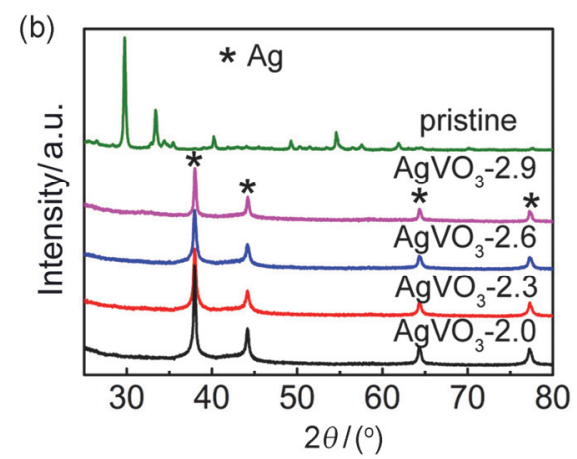

图 2 (a) $\mathrm{Li}^{-\mathrm{AgVO}_{3}}$ 一次电池的放电曲线; (b) $\mathrm{AgVO}_{3}$ 电极在图(a)所标注的 5 个放电状态下的 XRD 谱图

Figure 2 (a) Typical discharge curve of $\mathrm{Li}^{-\mathrm{AgVO}_{3}}$ primary battery. (b) XRD patterns of the $\mathrm{AgVO}_{3}$ electrodes at five discharge states as indicated in (a)

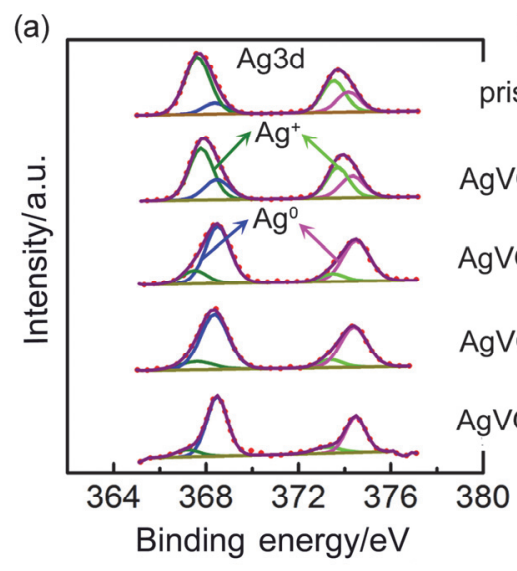

(b)

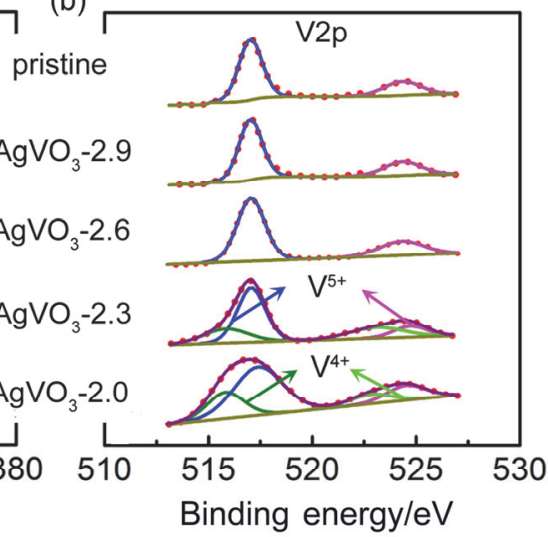

图 3 不同放电状态下 $\beta-\mathrm{AgVO}_{3}$ 电极的 XPS 谱图: (a) $\mathrm{Ag} 3 \mathrm{~d}$; (b) V2p

Figure 3 XPS spectra of (a) Ag3d and (b) V2p of the $\beta-\mathrm{AgVO}_{3}$ cathodes at different discharge states 
此外, 我们采用 SEM 和 TEM 表征了 $\mathrm{Li}-\mathrm{AgVO}_{3}$ 一 次电池中处于不同放电状态下的 $\mathrm{AgVO}_{3}$ 电极的形貌和 微观结构. 图 4(a) 4(e) 展示了不同放电状态的 $\mathrm{AgVO}_{3}$ 电极的 SEM 图像, 可以看出, 随着放电程度的加深, 电 极表面越来越粗糙. 当放电至 $2.9 \mathrm{~V}$ 时, $\mathrm{Ag}$ 颗粒开始从 电极表面析出. 随着放电过程的进行, $\mathrm{Ag}$ 颗粒的粒径不 断长大, 当放电至 $2.0 \mathrm{~V}$ 时, $\mathrm{Ag}$ 颗粒甚至出现团聚现象. $\mathrm{TEM}$ 图像也明显表明 $\mathrm{Ag}$ 颗粒的尺寸与放电深度呈正相 关关系, 从初始状态到放电结束, 银颗粒的粒径从几纳 米生长到几十纳米 [图 4(f) 4(j)]. 在初始状态的 $\mathrm{AgVO}_{3}$ 表面观察到直径约 $10 \mathrm{~nm}$ 左右的 $\mathrm{Ag}$ 颗粒[图 4(f)], 已有 文献报道这些 $\mathrm{Ag}$ 颗粒是由于 TEM 设备产生的高能电 子的轰击形成的 ${ }^{[33]}$. 当放电到 $2.9 \mathrm{~V}, \mathrm{Ag}$ 颗粒生长至 15 $\mathrm{nm}$ 左右[图 4(g)]. 随着持续放电, 银颗粒不断长大, 当 放电至 $2.0 \mathrm{~V}$ 时, $\mathrm{Ag}$ 颗粒最终生长至 $70 \mathrm{~nm}$ 左右 [图 4(j)]. 高分辨 TEM [HRTEM, 图 4(k) 4(o)]进一步显示了单质 银的晶格条纹, 其晶面间距 $0.24 \mathrm{~nm}$ 与立方相银单质的 (111) 晶面间距对应. 以上实验结果证明, 在放电过程 中, $\mathrm{AgVO}_{3}$ 中的 $\mathrm{Ag}^{+}$被还原成 $\mathrm{Ag}^{0}$ 并从钒氧化物体相中 析出到电极表面且随着放电程度加深不断长大. 其它形 态的银钒氧化物体系如 $\mathrm{Ag}_{2} \mathrm{VP}_{2} \mathrm{O}_{8}$ 在放电过程中也观察 到 $\mathrm{Ag}$ 纳米颗粒的析出, 并且纳米颗粒的尺寸和分布同 样受放电状态的影响 ${ }^{[25]}$.

处于不同放电状态下的 $\mathrm{Li}-\mathrm{AgVO}_{3}$ 一次电池被暴露 在 $\mathrm{O}_{2}$ 中直接用作可充 $\mathrm{Li}-\mathrm{O}_{2}$ 电池. 图 5(a) 是以不同放电 态的 $\mathrm{AgVO}_{3}$ 电极为空气正极的 $\mathrm{Li}-\mathrm{O}_{2}$ 电池在 100 $\mathrm{mA} \cdot \mathrm{g}_{\text {carbon }}{ }^{-1}$ 电流密度下的放电曲线. 以 $\mathrm{AgVO}_{3}-2.3$ 为正 极的 $\mathrm{Li}-\mathrm{O}_{2}$ 电池具有最高的比容量, 为 $9000 \mathrm{mAh}$ $\mathrm{g}_{\text {carbon }}{ }^{-1}$, 以 $\mathrm{AgVO}_{3}-2.0 、 \mathrm{AgVO}_{3}-2.6 、 \mathrm{AgVO}_{3}-2.9$ 和 pristine 为正极的 $\mathrm{Li}-\mathrm{O}_{2}$ 电池比容量分别为 7580、5920、 $5760 、 4450 \mathrm{mAh} \cdot \mathrm{g}_{\text {carbon }}{ }^{-1}$. 从图 5(b)和(c)可知, 在以 $\mathrm{AgVO}_{3}-2.3$ 为正极时得到了最小的充放电过电位 $1.27 \mathrm{~V}$, 其它 $\mathrm{Li}-\mathrm{O}_{2}$ 电池的充放电过电位按 $\mathrm{AgVO}_{3}$ 电极的放电深 度递减: $\mathrm{AgVO}_{3}-2.0<\mathrm{AgVO}_{3}-2.6<\mathrm{AgVO}_{3}-2.9<$ pristine,
分别为 $1.36 、 1.37 、 1.42 、 1.47 \mathrm{~V}$. 这是由于 $\mathrm{Li}-\mathrm{AgVO}_{3}$ 一次电池放电过程中银纳米颗粒的形成增强了电极的 导电性, 同时为 $\mathrm{Li}-\mathrm{O}_{2}$ 电池的氧还原氧析出反应 (ORR/OER)提供了活性中心. 银纳米颗粒的催化活性依 赖于其含量、尺寸与表面分布, 放电至 $2.3 \mathrm{~V}$ 时 $\mathrm{Ag}$ 生成 量、颗粒尺寸以及表面均匀分布达到较好平衡. 以 $\mathrm{AgVO}_{3}-2.3$ 为正极的 $\mathrm{Li}-\mathrm{O}_{2}$ 电池在 $300 \mathrm{~mA} \cdot \mathrm{g}_{\text {carbon }}{ }^{-1}$ 电流 密度下循环 95 圈后放电电压仍可以保持在 $2.0 \mathrm{~V}$ 以上 [图 5(d)], 表明电池具有较好的循环性能. 与图 5(d)相对 应的 $\mathrm{Li}-\mathrm{O}_{2}$ 电池的循环过程中的充放电曲线显示在图 5(e)中, 可看到电极极化逐渐增大. 其它放电状态的 $\mathrm{AgVO}_{3}$ 电极的循环性能见图 $\mathrm{S} 1$, 放电至 $2.0 \mathrm{~V} 、 2.6 \mathrm{~V}$ 、 $2.9 \mathrm{~V}$ 和初始电极分别稳定循环 69、56、51、35 周. 作 为对比, 以纯碳电极为正极的 $\mathrm{Li}-\mathrm{O}_{2}$ 电池的电化学性能 见图 S2, 其容量低、可逆循环次数少且充放电过电位高.

图 5(f)给出了不同放电态的 $\mathrm{AgVO}_{3}$ 电极的电化学 阻抗谱图(EIS), 可以看出电荷转移阻抗随着电极放电 深度加深而减小. $\mathrm{AgVO}_{3}-2.3$ 与 $\mathrm{AgVO}_{3}-2.0$ 电极的阻抗 值最小(约 $180 \Omega$ ), 表明其导电能力最强. 图 S3 显示了 $\mathrm{AgVO}_{3}-2.3$ 电极的倍率性能, 其中, 100 和 $200 \mathrm{~mA}$ $\mathrm{g}_{\text {carbon }}{ }^{-1}$ 电流密度下容量相差不大, 在 $500 \mathrm{~mA} \cdot \mathrm{g}_{\text {carbon }}{ }^{-1}$ 的电流密度下, 仍然可以得到高达 $8000 \mathrm{mAh} \cdot \mathrm{g}_{\text {carbon }}{ }^{-1}$ 的 比容量. 鉴于钒氧化物在 $\mathrm{Li}-\mathrm{O}_{2}$ 电池中较差的电催化活 性 ${ }^{[34]}$, 放电态 $\mathrm{AgVO}_{3}$ 在 $\mathrm{Li}-\mathrm{O}_{2}$ 电池中显著的电化学性能 主要归因于银纳米颗粒的生成, 其不仅提高了电极的电 导率也为 ORR/OER 催化反应提供了活性位点.

我们进一步分析了以 $\mathrm{AgVO}_{3}-2.3$ 电极为空气正极 的 $\mathrm{Li}-\mathrm{O}_{2}$ 电池的充放电产物的组成和形貌. 图 6(a)是 $\mathrm{Li}-\mathrm{O}_{2}$ 电池中放电状态和充电状态下的空气正极的 XRD 谱图, 电池进行第一圈放电后, 可以检测到 $\mathrm{Li}_{2} \mathrm{O}_{2}$ 的 XRD 特征峰，而当第一圈充电结束后， $\mathrm{Li}_{2} \mathrm{O}_{2}$ 的特征峰 消失, 这表明放电时生成 $\mathrm{Li}_{2} \mathrm{O}_{2}$, 随后的充电过程中 $\mathrm{Li}_{2} \mathrm{O}_{2}$ 又被分解. 这种可逆行为通过 XPS 被进一步证实

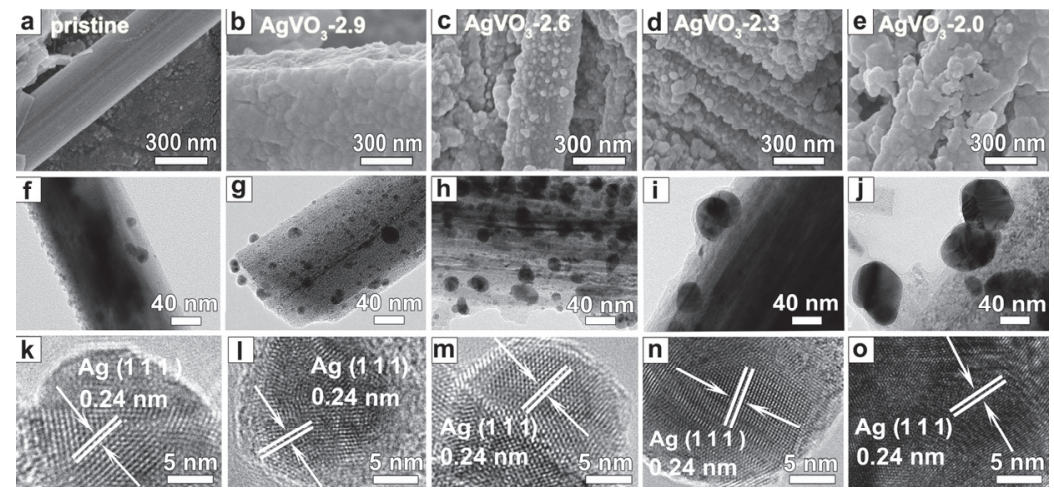

图 $4 \beta-\mathrm{AgVO}_{3}$ 电极在不同放电状态下[初始状态 $(\mathrm{a}, \mathrm{f}, \mathrm{k}), 2.9 \mathrm{~V}(\mathrm{~b}, \mathrm{~g}, \mathrm{l}), 2.6 \mathrm{~V}(\mathrm{c}, \mathrm{h}, \mathrm{m}), 2.3 \mathrm{~V}(\mathrm{~d}, \mathrm{i}, \mathrm{n})$ 和 $2.0 \mathrm{~V}(\mathrm{e}, \mathrm{j}, \mathrm{o})$ ] 的 $(\mathrm{a} \sim \mathrm{e}) \mathrm{SEM}$, (f $\left.\sim \mathrm{j}\right) \mathrm{TEM}$ 和 $(\mathrm{k} \sim \mathrm{o})$ HRTEM 图像

Figure $4 \quad(a \sim e)$ SEM, $(f \sim j)$ TEM and $(\mathrm{k} \sim 0)$ HRTEM images of the $\beta-\mathrm{AgVO}_{3}$ cathodes at different discharge states of $(\mathrm{a}, \mathrm{f}, \mathrm{k})$ pristine, $(\mathrm{b}, \mathrm{g}, 1) 2.9 \mathrm{~V}$, $(\mathrm{c}, \mathrm{h}, \mathrm{m}) 2.6 \mathrm{~V},(\mathrm{~d}, \mathrm{i}, \mathrm{n}) 2.3 \mathrm{~V}$ and $(\mathrm{e}, \mathrm{j}, \mathrm{o}) 2.0 \mathrm{~V}$, respectively 

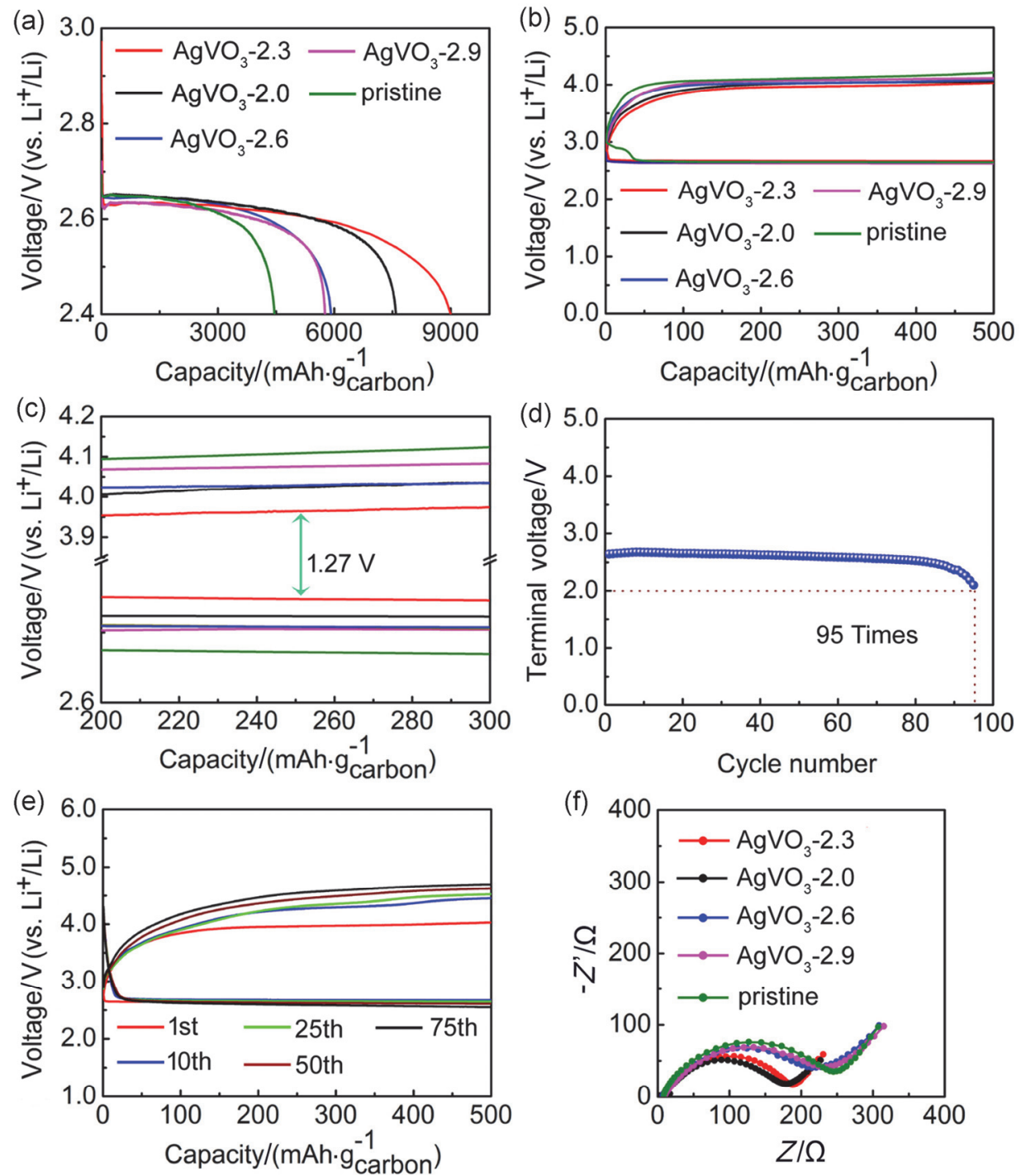

图 5 放电态 $\mathrm{AgVO}_{3}$ 电极在 $\mathrm{Li}_{-} \mathrm{O}_{2}$ 电池中的电化学性能: (a)电流密度为 $100 \mathrm{~mA} \cdot \mathrm{g}_{\text {carbon }}{ }^{-1}$ 截止电压为 $2.4 \mathrm{~V}$ 时的恒流放电曲线, (b) 电流密度为 300 $\mathrm{mA} \cdot \mathrm{g}_{\text {carbon }}{ }^{-1}$ 截止容量为 $500 \mathrm{mAh} \cdot \mathrm{g}_{\text {carbon }}{ }^{-1}$ 时的首圈充放电曲线, (c)充放电曲线图(b)的局部放大图, (d)电流密度为 $300 \mathrm{~mA} \cdot \mathrm{g}_{\text {carbon }}{ }^{-1}$ 时 $\mathrm{AgVO}_{3}-2.3$ 电 极不同周期的放电电压, (e)在 $300 \mathrm{~mA} \cdot \mathrm{g}_{\text {carbon }}{ }^{-1}$ 电流密度下以 $\mathrm{AgVO}_{3}-2.3$ 电极为正极的 $\mathrm{Li}-\mathrm{O}_{2}$ 电池的不同循环圈数的充放电曲线. (f) 不同放电状态下 的 $\mathrm{AgVO}_{3}$ 电极的电化学阻抗图

Figure 5 Electrochemical performance of the discharged $\mathrm{AgVO}_{3}$ electrodes in $\mathrm{Li}_{-} \mathrm{O}_{2}$ batteries: (a) the first galvanostatic discharge curves at 100 $\mathrm{mA} \cdot \mathrm{g}_{\text {carbon }}{ }^{-1}$ with a cut-off voltage of $2.4 \mathrm{~V}$, (b) discharge and charge curves of the first cycle at $300 \mathrm{~mA} \cdot \mathrm{g}_{\text {carbon }}{ }^{-1}$ with a cut-off capacity of $500 \mathrm{mAh} \cdot$ $\mathrm{g}_{\text {carbon }}{ }^{-1}$, (c) enlarged discharge-charge curves in (b), (d) discharge voltage of the $\mathrm{AgVO}_{3}-2.3$ electrode cycled at $300 \mathrm{~mA}^{-g_{\text {carbon }}}{ }^{-1}$ and (e) discharge-charge profiles at different cycles of the $\mathrm{Li}-\mathrm{O}_{2}$ battery with the $\mathrm{AgVO}_{3}-2.3$ electrode at $300 \mathrm{~mA} \cdot \mathrm{g}_{\text {carbon }}{ }^{-1}$ and with a specific capacity limit of $500 \mathrm{mAh} \cdot \mathrm{g}_{\text {carbon }}{ }^{-1}$. (f) Electrochemical impedance spectroscopies of the discharged $\mathrm{AgVO}_{3}$ electrodes at different states

[图 6(b)], 放电后在 $55.8 \mathrm{eV}$ 处检测到 $\mathrm{Li}_{2} \mathrm{O}_{2}$ 的 XPS 信号, 随着充电过程的完成, $\mathrm{Li}_{2} \mathrm{O}_{2}$ 的 XPS 信号消失 ${ }^{[35]}$. 为了直 观地观察充放电产物的生成与分解, 我们对充放电后的 正极材料进行了 SEM 测试. 图 6(c) 是放电后的 $\mathrm{AgVO}_{3}-2.3$ 电极的 SEM 图像, 观察到与文献报道类似的 典型圆饼状 $\mathrm{Li}_{2} \mathrm{O}_{2}$ 均匀分布在电极表面 ${ }^{[36,37]}$. 当电池进 行充电后, 圆饼状 $\mathrm{Li}_{2} \mathrm{O}_{2}$ 消失, 电极表面基本还原为初 始形貌 [图 6(d)], 与 XRD 和 XPS 测试结果相吻合. 上述 实验结果证明了 $\mathrm{Li}_{2} \mathrm{O}_{2}$ 的可逆生成与分解. 因此, 本工 作实验结果说明将放电态的 $\mathrm{Li}-\mathrm{AgVO}_{3}$ 一次电池继续用
作可充 $\mathrm{Li}-\mathrm{O}_{2}$ 电池是可行的, 这种方法能够提高一次电 池电极材料的利用率，同时有助于节约能源和资源.

\section{3 结论}

本工作证明放电态的 $\mathrm{Li}^{-\mathrm{AgVO}_{3}}$ 一次电池可以置于 $\mathrm{O}_{2}$ 中被作为 $\mathrm{Li}_{-} \mathrm{O}_{2}$ 电池再次利用. 在 $\mathrm{AgVO}_{3}$ 电极放电过 程中原位生成的银纳米颗粒增强了电极的导电性，同时 在 $\mathrm{Li}-\mathrm{O}_{2}$ 电池中作为氧还原和氧析出反应的电催化剂. 银颗粒的生成量以及尺寸和分布取决于电极的放电深 

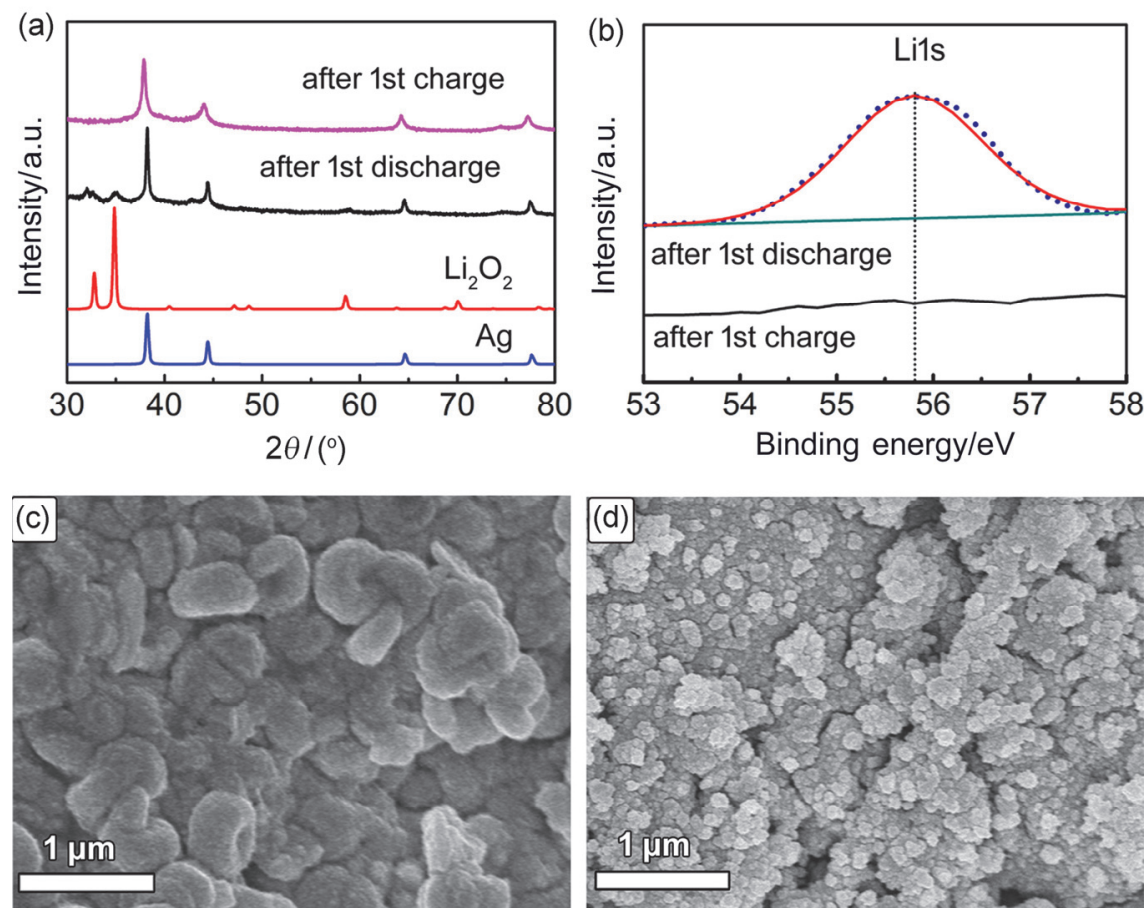

图 6 以 $\mathrm{AgVO}_{3}-2.3$ 电极为正极的 $\mathrm{Li}-\mathrm{O}_{2}$ 电池充放电产物表征: 充放电状态下电极的(a)XRD 谱图和(b)XPS 谱图, (c)放电后和(d)充电后的扫描电镜 图像

Figure 6 Characterization of the $\mathrm{Li}-\mathrm{O}_{2}$ battery with $\mathrm{AgVO}_{3}-2.3$ cathode: (a) XRD patterns and (b) XPS spectra at discharged and charged state, (c) SEM image after discharge, and (d) SEM image after recharge

度, 并对 $\mathrm{Li}-\mathrm{O}_{2}$ 电池的性能产生重要影响. 实验得出, 以 放电至 $2.3 \mathrm{~V}$ 的 $\mathrm{AgVO}_{3}-2.3$ 电极为正极的 $\mathrm{Li}-\mathrm{O}_{2}$ 电池表 现出最优异的电化学性能, 归因于电极表面银纳米颗粒 达到生成量、尺寸以及分布的平衡与优化. 将放电后废 弃的锂一次电池作为高容量 $\mathrm{Li}-\mathrm{O}_{2}$ 电池激活再生, 为高 附加值回收利用日益消耗的电池材料提供了一种新思 路，对于节约资源、降低污染具有重要意义.

\section{4 实验部分}

\section{1 样品制备}

参照文献 ${ }^{[22]}$, 通过水热加搅拌方法制备出了具有 纳米线形状的 $\beta-\mathrm{AgVO}_{3}$. 具体合成方法如下: $0.1872 \mathrm{~g}$ $\mathrm{NH}_{4} \mathrm{VO}_{3}$ (1.6 mmol, Aladdin)溶于 $16 \mathrm{~mL}$ 去离子水, 加 热到 $80{ }^{\circ} \mathrm{C}$ 直到完全溶解; 随后将等物质的量的 $\mathrm{AgNO}_{3}$ (0.2718 g, Aladdin) 溶解于 $16 \mathrm{~mL}$ 去离子水中. 在搅拌条 件下将 $\mathrm{NH}_{4} \mathrm{VO}_{3}$ 溶液逐滴滴加到 $\mathrm{AgNO}_{3}$ 溶液中形成黄 色沉淀. 滴加完毕后将所得到的前驱体搅拌 $30 \mathrm{~min}$ 然后 转移到 $50 \mathrm{~mL}$ 聚四氟乙烯内祄的高压釜中. 在摚拌下 $180{ }^{\circ} \mathrm{C}$ 油浴 $4 \mathrm{~h}$, 冷却至室温后将所得产物抽滤, 分别 用去离子水和乙醇洗涤, 随后在 $60{ }^{\circ} \mathrm{C}$ 下干燥 $10 \mathrm{~h}$, 获 得 $\beta-\mathrm{AgVO}_{3}$ 纳米线.

\section{2 电极制作和电池组装}

将质量比为 $3: 6: 1$ 的 $\beta-\mathrm{AgVO}_{3}$ 、导电碳(Super $\mathrm{P}$ carbon)和聚偏氟乙烯( $(\mathrm{PVdF})$ 分散在无水 $N$-甲基吡咯烷
酮溶剂中制成浆料，均匀地涂在泡沫镍集流体上, $110{ }^{\circ} \mathrm{C}$ 真空干燥 $10 \mathrm{~h}$, 得到所需工作电极. 为了便于实 现 $\mathrm{Li} / \mathrm{AgVO}_{3}$ 一次电池与 $\mathrm{Li}-\mathrm{O}_{2}$ 电池的直接转化, 我们参 照锂氧电池的常见组成 ${ }^{[38,39]}$, 以金属锂片为对电极、玻 璃纤维滤纸为隔膜、 $1 \mathrm{~mol} \cdot \mathrm{L}^{-1} \mathrm{LiTFSI} / \mathrm{TEGDME}$ 为电解 液, 在无水无氧的氩气气氛手套箱里组装成 CR-2032 型 扣式电池. 为了下一步引进氧气, 正极壳预先钻几个分 布均匀的气孔并用胶带密封。通过控制放电终压将 $\mathrm{Li}-\mathrm{AgVO}_{3}$ 电池以 $100 \mathrm{~mA} \cdot \mathrm{g}^{-1}$ 电流密度放电至不同状态. $\mathrm{Li}-\mathrm{AgVO}_{3}$ 电池被放电到 $2.9 \mathrm{~V} 、 2.6 \mathrm{~V} 、 2.3 \mathrm{~V} 、 2.0 \mathrm{~V}$, 得 到的正极材料相应地表示为 $\mathrm{AgVO}_{3}-2.9 、 \mathrm{AgVO}_{3}-2.6$ 、 $\mathrm{AgVO}_{3}-2.3$ 和 $\mathrm{AgVO}_{3}$-2.0. 随后, $\mathrm{Li}-\mathrm{AgVO}_{3}$ 电池被暴露 在氧气中直接作为可充 $\mathrm{Li}-\mathrm{O}_{2}$ 电池再次使用. 在 LANDCT200A 电池性能测试设备上进行室温下两种电 池的恒电流充放电测试.

\section{3 表征测试}

采用 X 射线粉末衍射仪 (XRD, MiniFlex600)和透射 电子显微镜(TEM, Philips Tecnai F20)对 $\mathrm{AgVO}_{3}$ 样品和 放电态的 $\mathrm{AgVO}_{3}$ 电极的结构进行表征. 采用扫描电子 显微镜(SEM, JEOL JSM7500F) 对 $\mathrm{AgVO}_{3}$ 样品和不同放 电态的 $\mathrm{AgVO}_{3}$ 电极的形貌进行表征. 采用 $\mathrm{X}$ 射线光电 子能谱(XPS, PerkinElmer PHI 1600 ESCA)表征不同放 电状态 $\mathrm{AgVO}_{3}$ 电极的化学组成变化. 


\section{References}

[1] Takeuchi, K. J.; Marschilok, A. C.; Davis, S. M.; Leising, R. A.; Takeuchi, E. S. Coord. Chem. Rev. 2001, 219, 283.

[2] Cheng, F.; Chen, J. J. Mater. Chem. 2011, 21, 9841.

[3] Han, C.; Pi, Y.; An, Q.; Mai, L.; Xie, J.; Xu, X.; Xu, L.; Zhao, Y. Nano Lett. 2012, 12, 4668.

[4] Liang, S.; Zhou, J.; Pan, A.; Li, Y.; Chen, T.; Tian, Z.; Ding, H. Mater. Lett. 2012, 74, 176.

[5] Zeng, H.; Wang, Q.; Rao, Y. RSC Adv. 2015, 5, 3011.

[6] Kang, D. H.; Chen, M.; Ogunseitan, O. A. Environ. Sci. Technol. 2013, 47, 5495.

[7] Liu, Q.; Xu, J.; Xu, D.; Zhang, X. Nat. Commun. 2015, 6, 7892.

[8] Armand, M.; Tarascon, J. M. Nature 2008, 451, 652.

[9] Sen, X.; Guo, Y.; Wan, L. Scientia Sinica Chimica 2011, 41, 1229.

[10] Zhang, Z.; Li, L.; Ren, Q.; Xu, Q.; Cao, B. Chin. J. Chem. 2016, 34, 631.

[11] Zhang, Y.; Li, Y.; Xia, X.; Wang, X.; Gu, C.; Tu, J. Sci. China Tech. Sci. 2015, 58, 1809.

[12] Chen, J.; Cheng, F. Acc. Chem. Res. 2009, 42, 713.

[13] Wang, Y.; Yi, J.; Xia, Y. Adv. Energy Mater. 2012, 2, 830.

[14] Gu, D.; Zhang, C.; Gu, S.; Zhang, Y.; Wang, Y.; Qiang, L. Acta Chim. Sinica 2012, 70, 2115. (顾大明, 张传明, 顾硕, 张音, 王余, 强亮生, 化学学报, 2012, 70, 2115.)

[15] Cao, Y.; Wei, Z.; He, J.; Zang, J.; Zhang, Q.; Zheng, M.; Dong, Q. F. Energy Environ. Sci. 2012, 5, 9765.

[16] Cheng, F.; Chen, J. Chem. Soc. Rev. 2012, 41, 2172.

[17] Zhang, D.; Zhang, C. Z.; Mu, D. B.; Wu, B. R.; Wu, F. Prog. Chem. 2012，24，2472. (张栋, 张存中, 穆道斌, 吴伯荣, 吴锋, 化学进 展, 2012, 24, 2472.)

[18] Cheng, F.; Chen, J. Acta Chim. Sinica 2013, 71, 473. (程方益, 陈 军, 化学学报, 2013, 71, 473.)

[19] Yang, F.; Liu, Q.; Xu, J.; Zhao, M.; Zhang, X. Chin. Sci. Bull. 2013, 58,3199 . (杨凤玉, 刘清朝, 徐吉静, 赵敏寿, 张新波, 科学通报, 2013, 58, 3199.)

[20] Jin, Q.; Pei, L; Hu, Y.; Du, J.; Han, X.; Cheng, F.; Chen, J. Acta Chim. Sinica 2014, 72, 920. (靳琪, 裴龙凯, 胡宇翔, 杜婧, 韩晓 鹏, 程方益, 陈军, 化学学报, 2014, 72, 920.)
[21] Hu, Y.; Zhang, T.; Cheng, F.; Zhao, Q.; Han, X.; Chen, J. Angew. Chem. Int. Ed. 2015, 54, 4338.

[22] Zhang, S.; Li, W.; Li, C.; Chen, J. J. Phys. Chem. B 2006, 110, 24855.

[23] Bao, Q.; Bao, S.; Li, C. M.; Qi, X.; Pan, C.; Zang, J.; Wang, W.; Tang, D. Y. Chem. Mater. 2007, 19, 5965.

[24] Xu, Y.; Han, X.; Zheng, L.; Wei, S.; Xie, Y. Dalton Trans. 2011, 40, 10751.

[25] Kirshenbaum, K.; Bock, D. C.; Lee, C. Y.; Zhong, Z.; Takeuchi, K. J.; Marschilok, A. C.; Takeuchi, E. S. Science 2015, 347, 149.

[26] Wittmaier, D.; Cañas, N. A.; Biswas, I.; Friedrich, K. A. Adv. Energy Mater. 2015, 5, 1500763.

[27] Zhang, D.; Zhang, C.; Mu, D.; Wu, B.; Wu, F. Acta Chim. Sinica 2013, 71, 1101. (张栋, 张存中, 穆道斌, 吴伯荣, 吴峰, 化学学 报, 2013, 71, 1101.)

[28] Kumar, S.; Selvaraj, C.; Scanlon, L. G.; Munichandraiah, N. Phys. Chem. Chem. Phys. 2014, 16, 22830.

[29] Cui, Q.; Zhang, Y.; Peng, Z. Chem. Res. Chin. Univ. 2016, 32, 106.

[30] Lu, J.; Cheng, L.; Lau, K. C.; Tyo, E.; Luo, X.; Wen, J.; Miller, D.; Assary, R. S. Nat. Commun. 2014, 5, 4895.

[31] Park, J. B.; Luo, X.; Lu, J.; Shin, C. D.; Yoon, C. S.; Amine, K.; Sun, Y. K. J. Phys. Chem. C 2015, 119, 15036.

[32] Rozier, P.; Savariault, J. M.; Galy, J. J. Solid State Chem. 1996, 122, 303.

[33] Song, J.; Lin, Y.; Yao, H.; Fan, F.; Li, X.; Yu, S. ACS Nano 2009, 3 , 653.

[34] Lim, S. H.; Kim, B. K.; Yoon, W. Y. J. Appl. Electrochem. 2012, 42, 1045.

[35] Li, F.; Tang, D.-M.; Zhang, T.; Liao, K.; He, P.; Golberg, D.; Yamada, A.; Zhou, H. Adv. Energy Mater. 2015, 5, 1500294.

[36] Cui, Q.; Zhang, Y.; Ma, S.; Peng, Z. Sci. Bull. 2015, 60, 1227.

[37] Liu, Q.; Jiang, Y.; Xu, J.; Xu, D.; Chang, Z.; Yin, Y.; Liu, W.; Zhang, X. Nano Res. 2015, 8, 576.

[38] Shao, X.; Zhang, T.; Wen, Z. Chin. J. Chem. 2017, 35, 35.

[39] Jiang, J.; Liu, X.; Zhao, S.; He, P.; Zhou, H. Acta Chim. Sinica 2014, 72, 417. (蒋颕，刘晓飞，赵世勇，何平，周豪慎，化学学报, 2014, 72, 417.)

(Cheng, B.) 